\title{
Acetabular Reconstruction in Total Hip Arthroplasty
}

\author{
Won Yong Shon, MD, PhD, Siva Swaminathan Santhanam, MD, Jung Woo Choi, MD \\ Department of Orthopedic Surgery, Korea University Guro Hospital, Seoul, Korea
}

The difficulties encountered in dealing with the bone deficient acetabulum are amongst the greatest challenges in hip surgery. Acetabular reconstruction in revision total hip arthroplasty can successfully be achieved with hemispherical components featuring a porous or roughened ingrowth surface and options for placement of multiple screws for minor acetabular defect. Acetabular component selection is mostly based on the amount of bone loss present. In the presence of combined cavitary and segmental defects without superior acetabular coverage, reconstructions with a structural acetabular allograft protected by a cage or a custom-made triflange cage have been one of preferred surgical options. The use of a cage or ring over structural allograft bone for massive uncontained defects in acetabular revision can restore host bone stock and facilitate subsequent rerevision surgery to a certain extent. But high complication rates have been reported including aseptic loosening, infection, dislocation and metal failure. On the other hand, recent literature is reporting satisfactory outcomes with the use of modular augments combined with a hemispherical shell for major acetabular defect. Highly porous metals have been introduced for clinical use in arthroplasty surgery over the last decade. Their higher porosity and surface friction are ideal for acetabular revision, optimizing biological fixation. The use of trabecular metal cups in acetabular revision has yielded excellent clinical results. This article summarizes author's experience regarding revision acetabular reconstruction options following failed hip surgery including arthroplasty.

Key Words: Total hip arthroplasty, Acetabular reconstruction, Revision, Allograft

\section{INTRODUCTION}

Bone deficiency in revision total hip arthroplasty (THA) is a challenge to the surgeon. The management

Submitted: December 24, 2015 1st revision: January 23, 2016

Final acceptance: February 1, 2016

Address reprint request to

Won Yong Shon, MD, PhD

Department of Orthopaedic Surgery, Korea University Guro

Hospital, 148 Gurodong-ro, Guro-gu, Seoul 08308, Korea

TEL: +82-2-2626-1163 FAX: +82-2-2626-1163

E-mail: shonwydahotmail.com

This is an Open Access article distributed under the terms of the Creative Commons Attribution Non-Commercial License (http://creativecommons. org/licenses/by-nc/4.0) which permits unrestricted non-commercial use, distribution, and reproduction in any medium, provided the original work is properly cited. of severe acetabular deficiency at revision arthroplasty, complex primary total hip replacement after postinfective or post-traumatic sequelae remains a complex problem. The purpose of the acetabular reconstruction is to obtain a stable, durable fixation of a new socket to reestablish the center of rotation and, if possible, restore bone stock.

Traditionally, major acetabular defects have been reconstructed for primary and revision THA by impaction bone grafting (IBG) and a cemented socket ${ }^{1}$. The midterm and long-term results of IBG have generally been favorable ${ }^{2}$. However, it generally requires a contained defect. But there are some reports of poor results when impaction grafting has been used ${ }^{33}$.

There are different options to overcome the problem of acetabular deficiency. Porous-coated cementless acetabular 
cups or cemented cup fixation can be used with or without a cancellous bone graft for simple acetabular defects, either cavitary or segmental.

However, combined cavitary and segmental defects are more challenging, particularly those without superior acetabular coverage precluding the use of a conventional cementless, non-augmented socket. Combined defects may be managed with reconstruction cages or structural bone grafts. However, the reconstructive procedure is demanding in the absence of a sufficient amount of bone. Such defects have been addressed with the use of structural allograft, highly porous metal shells with or without a cage, or the use of a custom triflange cup ${ }^{4,5}$.

The long-term results of revision surgery with these reconstructive options have been suboptimal due to the lack of bony in-growth of the cage or custom-made triflange cup to the deficient iliac bone ${ }^{6}$. Furthermore, the host tissue may resorb the allograft.

Flexible reconstruction meshes can be used to convert uncontained defects into contained defects, thus providing a stable cavity for IBG reconstruction and cemented cup fixation. The use of IBG for the reconstruction of acetabular defects with and without the use of adjuvant metal meshes was described by Slooff et al ${ }^{1}$. However, this technique has been used limitedly.

Recently new porous metal cups, shells and augments such as the most commonly used Trabecular Metal ${ }^{7)}$ (Zimmer, Warsaw, IN, USA) components have been developed. These systems provide a biologic fixation method, allow extensive bony in-growth and have a high initial frictional resistance to mechanical loosening. The goal of all of these modifications is to promote firm fixation of the acetabular component to the bony pelvis and to prevent future loosening of the acetabular component ${ }^{8)}$.

This article presents our experience in acetabular revision surgery. We reviewed the indications and results of each acetabular reconstruction option in the literature. We also present our early experience with the newer Trabecular Metal (TM) cups and augments.

\section{PREOPERATIVE EVALUATION}

Thorough preoperative patient assessment is critical in cases requiring acetabular component revision, and patient history is a key component.

The lack of a pain-free interval following primary THA may prompt questioning of the indication for surgery, or it may indicate the presence of low-grade sepsis. Deep infection must be ruled out. Serum erythrocyte sedimentation rate (ESR; normal, $<20 \mathrm{mg} / \mathrm{dL}$ ) and C-reactive protein (CRP; normal, $<10 \mathrm{mg} / \mathrm{dL}$ ) should be obtained in all revision patients.

Preoperative radiographic assessment requires projections that include the entire prosthesis. An antero-posterior (AP) pelvis radiograph, a lateral hip view and both oblique view are usually needed in small lysis or bone defect. AP radiograph is sensitive in detecting clinically significant osteolytic lesion with further increase in sensitivity with addition of oblique radiographic views and are thus effective screening tools. However, if the osteolytic volume in early computed tomography (CT) scan exceeds more about than $1,000 \mathrm{~mm}^{3}$, it should raise caution and regular monitoring of progression of lesion is required and some curtailment of patient's activity level should be considered ${ }^{9,10)}$.

CT and three-dimensional (3D) CT should be taken as an adjunct in hips with major osteolysis and pelvic bone loss. 3D CT imaging can give the operating surgeon an improved preoperative understanding of the anatomical findings in severe complicated acetabular bony defect and makes it easier to select appropriate reconstructive implant and augments.

In cases in which the acetabular component is medial to the Kohler line, retained cement may be present, and/or previous screws are present and hence Judet views and/or a 3D CT reconstruction with contrast are valuable to evaluate the pelvic vessels, ureter, and bladder and their proximity to the acetabular component.

\section{LABORATORY EVALUATION}

All revision candidates should be pre-operatively evaluated in the same fashion. Screening laboratory tests include a complete blood count (CBC), ESR, and CRP. If both the CRP and the ESR are elevated, the hip should be aspirated prior to surgery.

\section{SURGICAL EXPOSURES}

Revision of the acetabular component presents several challenges, including safe removal of existing implants and cement, stable implantation of revision prostheses and bone graft, and preservation of the soft-tissue envelope and abductor mechanism. These challenges might require special, more extensile approaches and might not be sufficiently addressed with the conventional 


\section{Hip \& Pelvis}

Won Yong Shon et al. Acetabular Reconstruction in Total Hip Arthroplasty

approaches used for primary hip arthroplasty.

The posterolateral approach is a universal approach that can be used for simple cup revisions and for more complex revisions requiring structural allograft. This approach requires release and subsequent repair of the external rotators and posterior capsule. The acetabulum is exposed by retracting the femur anteriorly. Adequate mobilization of the proximal femur might require several soft-tissue releases, including insertion of the gluteus maximus on the posterior femur, the anterior capsule, and the reflected head of the rectus femoris. The advantages of this approach are preservation of the abductors and good exposure to the proximal femur and acetabulum, including the ischium and posterior column. There is limited exposure however, to the anterior column.

In case of severe intra-pelvic migration of acetabular component, retroperitoneal approach or trans-abdominal approach should be considered to prevent several serious intra-pelvic complications, including vascular injuries, which have been reported when acetabular component removal was attempted through the defect in the inner wall of pelvis ${ }^{11)}$ (Fig. 1).

\section{CEMENTLESS HEMISPHERIC ACETABULAR RECONSTRUCTION}

Acetabular reconstruction in revision THA can successfully be achieved with hemispherical components featuring a porous or roughened in-growth surface and options for placement of multiple screws.

Most acetabular revisions can be performed with a hemispherical shell, or with a large acetabular component, or so called "jumbo" ( $\geq 66 \mathrm{~mm}$ for men, $\geq 62 \mathrm{~mm}$ for women) coupled with IBG. A cementless porous-coated hemispheric metal acetabular implant is usually suitable for defects that can be contained, rendered contained, or where rim fixation can be achieved (Paprosky type I and II bone defects [type 1 and 2 in American Association of Orthopaedic Surgeons classification]), with supplementary screw fixation (Fig. 2).
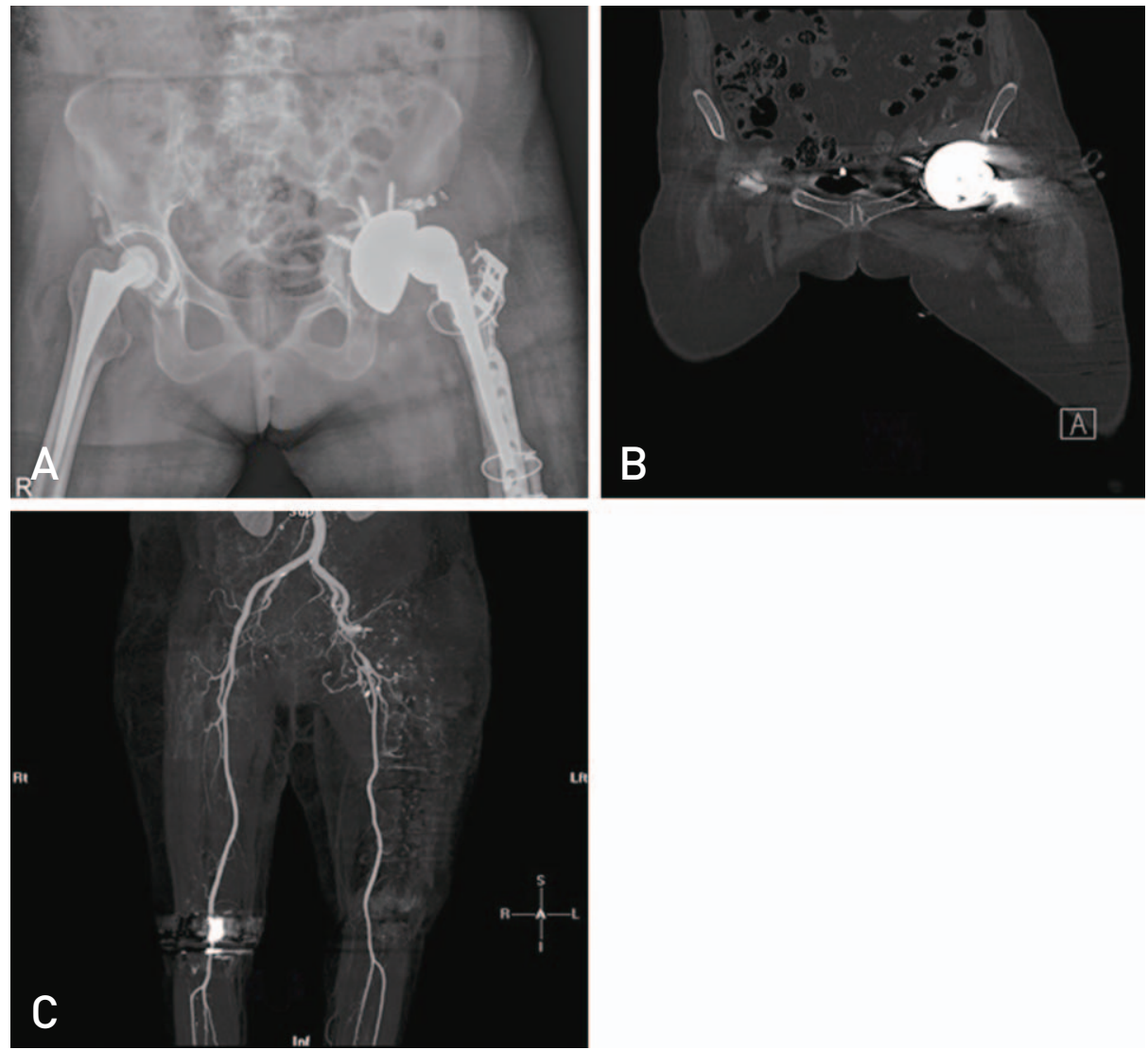

Fig. 1. (A, B) Radiograph and computed tomography (CT) scan respectively showing intra-pelvic acetabular protrusion with screw. (C) This patient sustained injury to the external iliac artery during acetabular component retrieval which is seen in the CT angiogram image. 


\section{Hip \& Pelvis}

Hip Pelvis 28(1): 1-14, 2016

However a cementless component alone may not be sufficient in type III defects. In type III A defects, durable biologic conditions for bone in-growth can only be achieved if the contact of the component with the remaining host bone is more than $40-60 \%$. Its use is contraindicated where bony in-growth and initial stability is not possible, such as severe type III defects in which large bone defects may be present in the anterior and posterior columns or large superior acetabular defect. Cementless components are also avoided in severe osteoporosis, irradiation and pelvic discontinuity.

Following adequate exposure, any granulomatous tissue or pseudo-membrane is excised and the acetabulum is prepared using hemispherical reamers. Drilling of the sclerotic bone can be used to encourage healthy bleeding. Isolated cavitary defects and other areas of bone stock deficiency are densely packed with morsellized cancellous bone ( 1 to $10 \mathrm{~mm}$ fresh-frozen non-irradiated femoral head allograft). Morcellized bone graft is impacted into the defect with reverse reaming.

Primary fixation of cementless acetabular component is key factor for success of this technique and IBG is only supplementary procedure because in order to obtain a better press-fit, a porous-coated titanium cup 1 to $2 \mathrm{~mm}$ larger than the last trial is routinely used. Regardless of how stable the prosthesis appears, fixation is supplemented using a minimum of two screws. Large acetabular defects and an inability to obtain greater than $50 \%$ host bone contact have normally been deemed inappropriate for reconstruction using hemispherical cups and IBG alone; however, there are studies which provide evidence to the contrary ${ }^{12)}$.

The disadvantages are that extra-large sockets limit bone-stock restoration, and large, oblong bone deficiencies cannot be filled in an inferior-to-superior direction without extensive reaming of the anterior or posterior column or superior placement of the cup because many superior defects are oblong, and their supero-inferior dimension is larger than their AP dimension and converting the oblong to a hemisphere with progressive reaming might disrupt the posterior wall and column, which are critical for implant stability.

In the authors' experience, it is possible to achieve press fit stability on the rim of an acetabulum with impaction grafting but IBG of acetabular defects in revision THA may not always provide a reliable bone stock in the long
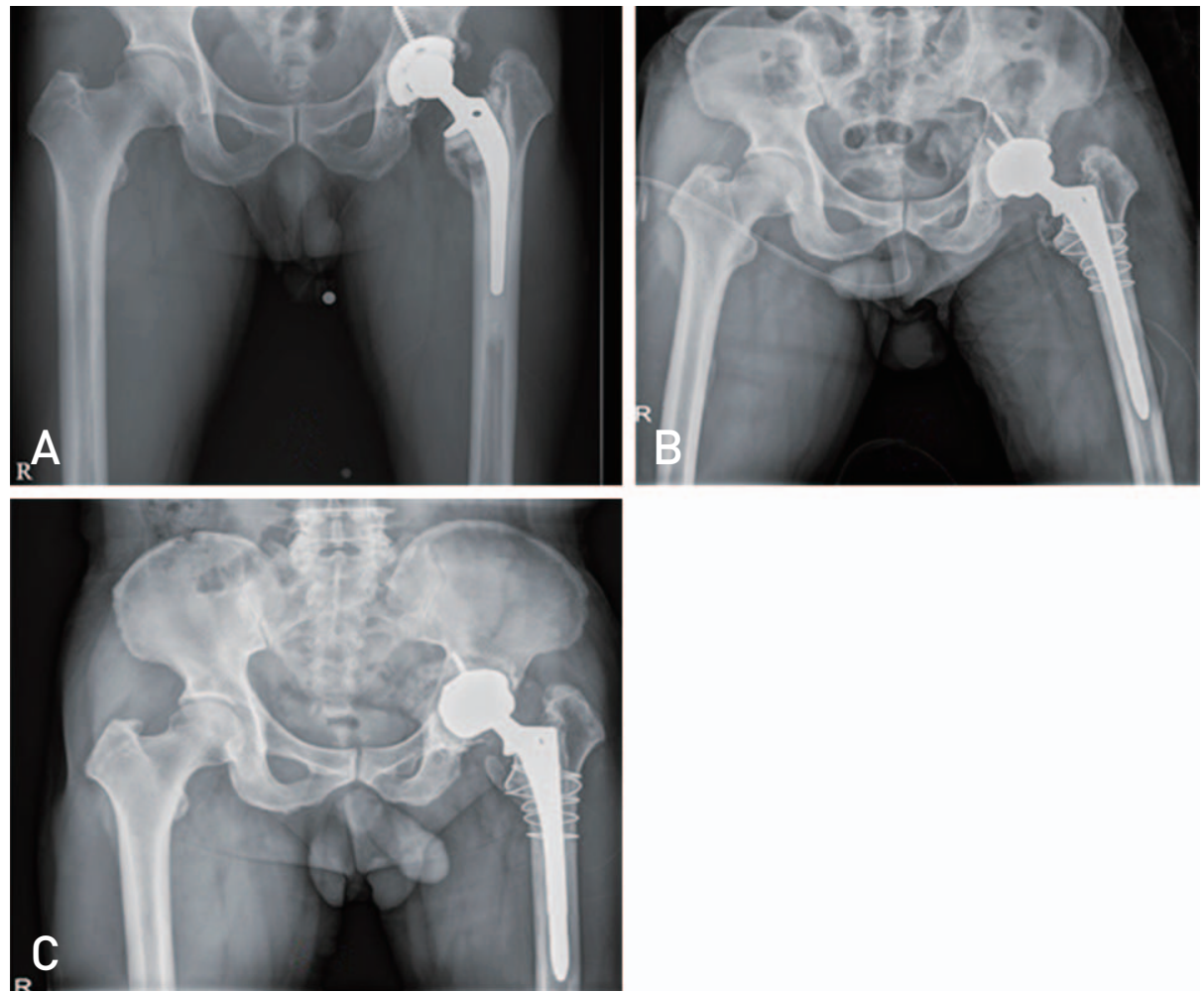

Fig. 2. (A) Radiograph showing lysis around acetabular and femoral component. (B) Radiograph taken after revision with cementless acetabular and femoral components. (C) Follow up radiograph at 2 years showing loosening of acetabular component. 


\section{Hip \& Pelvis}

Won Yong Shon et al. Acetabular Reconstruction in Total Hip Arthroplasty

run (Fig. 3).

Cementless implants permit in-growth of host bone whilst remodelling occurs at the metal-bone interface; this leads to durable and stiff biological fixation. Cementless revision of the failed acetabular component yields excellent long-term results. IBG allows bone restoration medially and into segmental defects, whilst the press fit is still achieved on the rim of the socket. This technique, combined with a cementless porouscoated component with supplementary screw fixation, is now a well-established method for acetabular revision in the context of restoring bone stock.

According to authors' experience, fresh frozen bone seems to yield the best results. However, there is a risk of transmission of contagious diseases when fresh frozen grafts are used. To negate this one may use processed bone, which consists of irradiated and freeze-dried bone. Both of these processing methods impair the biomechanical properties of the graft and may affect bone incorporation disadvantageously ${ }^{13)}$.
Different preparations of allograft may be used to reconstruct acetabular bone deficiencies. Freeze-drying allografts reduces graft immunogenicity and enhances graft incorporation. However, with freeze-dried grafts (vs. fresh-frozen allografts), remodeling and revascularization are delayed. Furthermore, freeze-drying can reduce the mechanical properties of the graft and diminish its capacity for structural support ${ }^{14,15}$.

Biomechanically, morsellised allograft has a high capacity to incorporate in animal models dependent upon achieving initial adequate stability in the construct. However subsequent loss of stability despite initial incorporation has been reported ${ }^{16}$.

There is interest in the use of demineralised bone matrix and bone morphogenic proteins in IBG, but published evidence is scarce. Only one clinical study with short-term follow-up reports the use of this combination in association with morsellised allograft in acetabular revision ${ }^{17}$.

Between 2000 and 2014, we performed 111 cases of
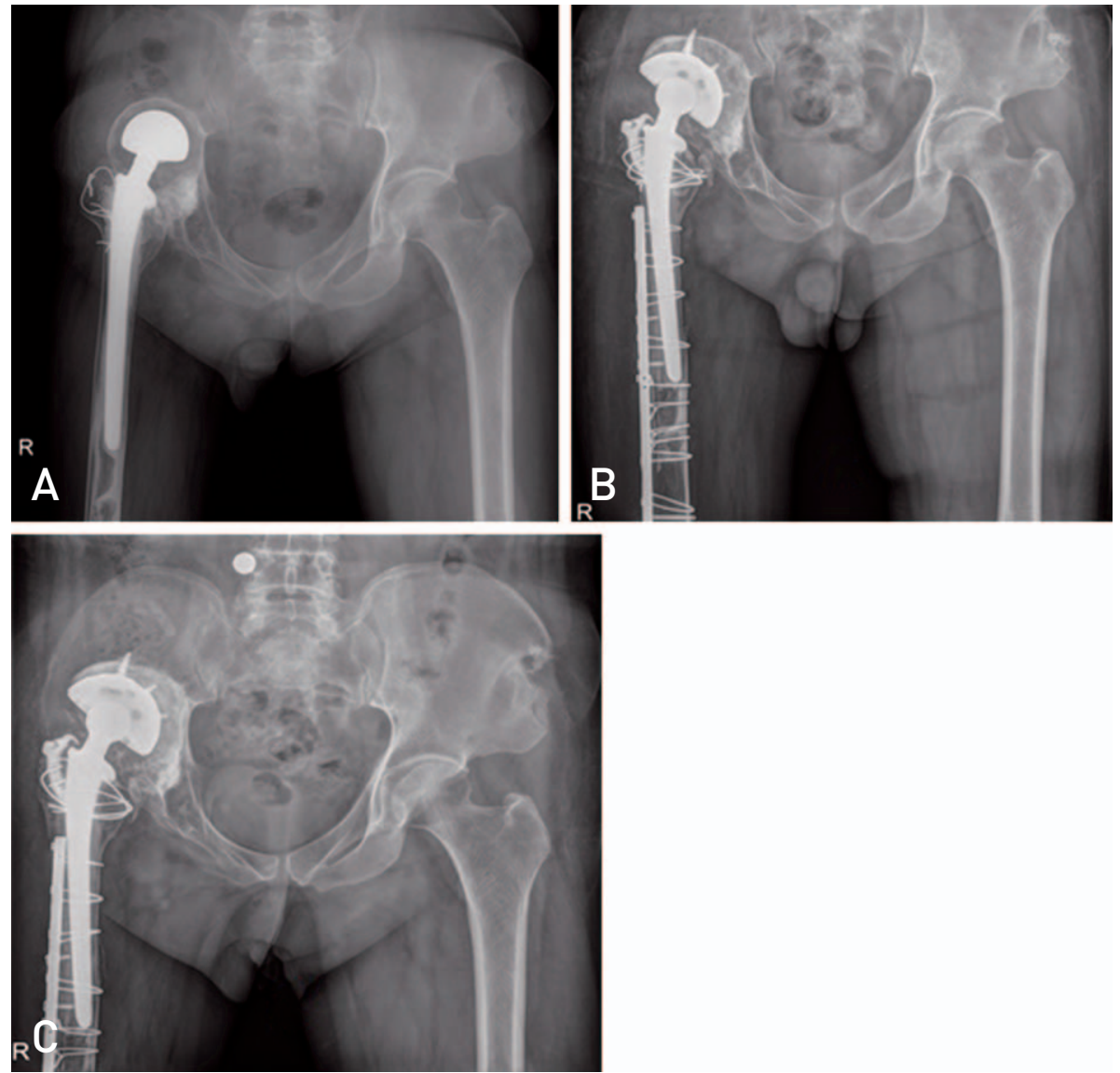

Fig. 3. (A) Radiograph showing severe cavitary defect in the right acetabulam. (B) Follow up radiograph at one year after revision done using impaction bone grafting and cementless acetabular cup. (C) Follow up radiograph at 3 years showing superior migration of cementless acetabular cup with resorption of the allograft. 


\section{Hip \& Pelvis}

Hip Pelvis 28(1): 1-14, 2016

revision with cementless acetabular cups. Out of the 111 cases, 9 cases required re-revision. Two cases of aseptic cup loosening, 1 case of metallosis with pseudotumor, 4 cases of structural allograft failure and 2 cases of infection being the respective causes. Our results were inferior compared to some previous studies. IBG of acetabular defects in revision THA may not always provide a reliable bone stock in long-term.

\section{STRUCTURAL ALLOGRAFT RECONSTRUCTION}

Acetabular fixation during revision THA in patients who have a non-supportive superior dome and proximal migration of the acetabular component (Paprosky type III A defect) cannot be achieved reliably with use of a hemispherical porous coated component alone. A high rate of failure has been noted when an unsupported porous-coated acetabular component has been inserted without an associated structural graft ${ }^{18,19}$. The high rate of failure is believed to be secondary to a lack of superior dome support with subsequent component micro-motion and/or superolateral migration.
To restore bone stock, bone grafts are always used (Fig. 4). Autografts are superior to allografts with respect to their incorporation capacity. Structural bone autografting is still a gold standard for type III acetabular defect in dysplastic hip arthroplasty. However, in revision cases, autografts are not always available. Thus, allograft bone is widely used. The allografts used in acetabular reconstruction can be divided into two groups: bulk allografts and morsellized allografts with mesh ${ }^{20)}$.

In general, structural grafts replacing more than $50 \%$ of the acetabulum require protection by a cage. Contained defects may however be large enough to require extensive morsellized bone grafting preventing contact between bleeding host bone and an uncemented cup. Under these circumstances a cage is necessary (Fig. 5). Uncontained (segmental) defects are classified as greater or less than $50 \%$ of the acetabulum; therefore they can be of any size. They may require a structural graft. The use of bulk allografts is controversial and restricted usually to cases of massive bone $\operatorname{loss}^{21,22)}$. In 1994, Paprosky and Magnus ${ }^{23)}$ published the results of severe acetabular defect with cemented component and allografts wherein
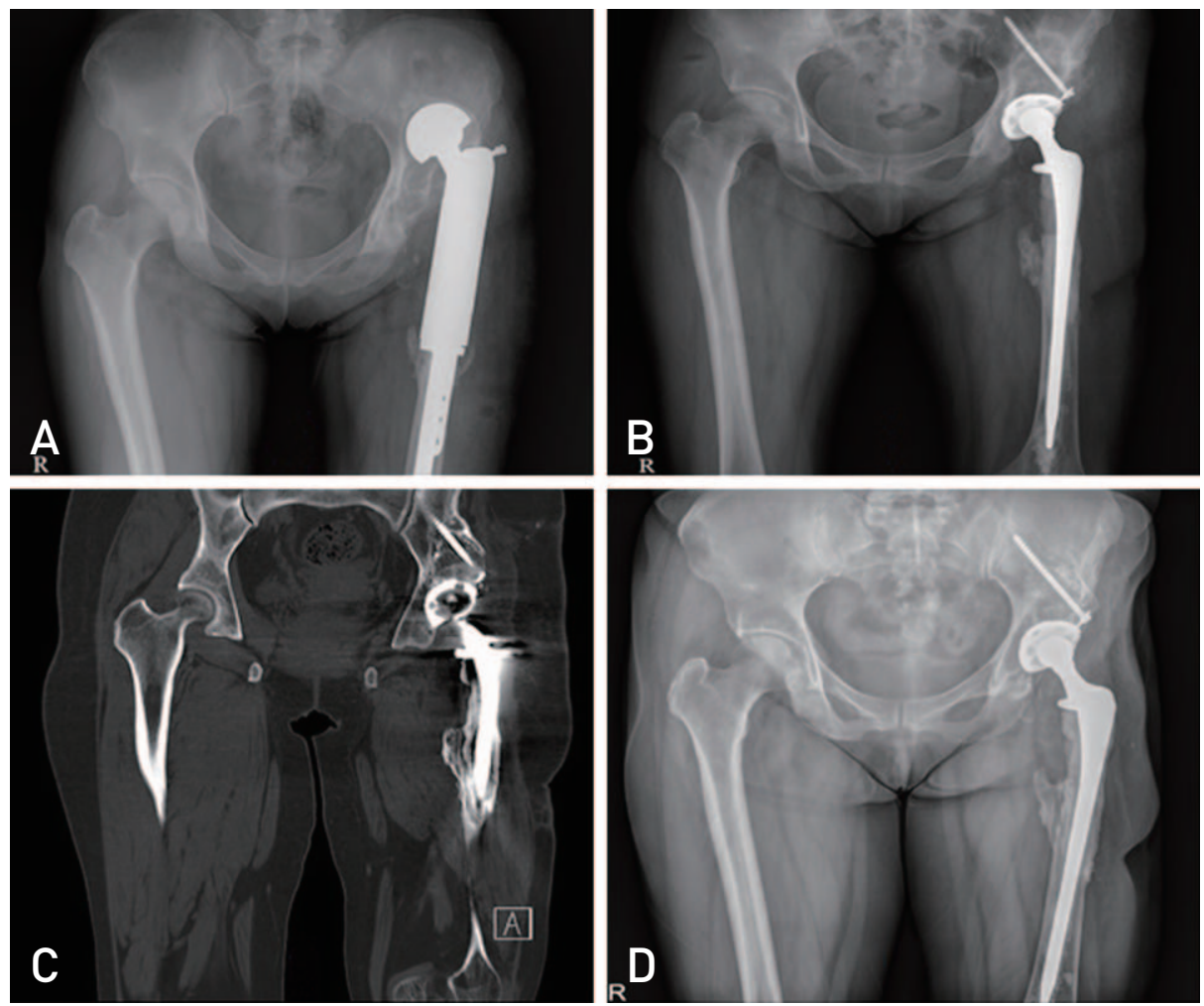

Fig. 4. (A) Radiograph showing a failed bipolar tumor prosthesis with a severe superior acetabular defect. (B) Radiograph taken after revision with structural allograft and a cementless acetabular cup. (C) Computed tomography scan image showing well incorporated graft, 6 years after revision surgery. (D) Radiograph taken at 8 years after revision surgery showing well-functioning implants with no evidence of loosening. 


\section{Hip \& Pelvis}

Won Yong Shon et al. Acetabular Reconstruction in Total Hip Arthroplasty

they attained satisfactory results.

Sporer et al. ${ }^{24)}$ and O'Rourke et al. ${ }^{25)}$ described a technique of using either distal femoral or proximal tibial allograft and cementless cups to reconstruct the acetabulum. This technique involves contouring the graft in the shape of ' 7 ' and fixing the superior limb to the ilium with cancellous screws. These grafts are selected for structural support because orientation of the trabecular bone provides better mechanical support for the implant compared with a femoral head allograft. The screws are oriented obliquely in the direction of loading to provide compression of the graft against the ilium. Furthermore, the extra-acetabular screws do not interfere with reaming. The acetabular cavity is then reamed to accept a press-fit cup secured with multiple screws. Sporer et al. ${ }^{24)}$ reported on use of the technique in 23 acetabular reconstructions performed for Paprosky type IIIA defects (non-supportive superior dome, superolateral migration of the acetabular component more than $3 \mathrm{~cm}$ above the obturator line). At a mean follow-up of 10 years, 5 of the 23 reconstructions were revised for aseptic loosening. With radiographic signs of loosening as the endpoint, 10-year construct survival was $74 \%$. They concluded that acetabular revision with use of a porous-coated acetabular component along with a structural distal femoral allograft for the treatment of a type-III A defect demonstrated a high rate of clinical and radiographic success after an average of ten years of follow-up. However, revascularization of the allograft with subsequent resorption has been reported ${ }^{26}$.

It has been noted that the failure rate is high when structural grafts support large areas $(>50 \%)$ of the acetabular component. Garbuz et al. ${ }^{27)}$ reported on 33 acetabular revisions reconstructed with massive acetabular allograft (it supported $>50 \%$ of the cup in each case). At a mean follow-up of 7 years, 15 hips needed a repeat revision ( $45 \%$ failure rate) because of failure of the prosthesis ( 7 hips) or failure of both prosthesis and allograft ( 8 hips).

In our experience, five patients who had an acetabular reconstruction with use of fresh frozen femoral head or a distal femoral allograft for the treatment of a type-III B defect, with failed acetabular revision surgery with a cage and allograft were followed annually with clinical
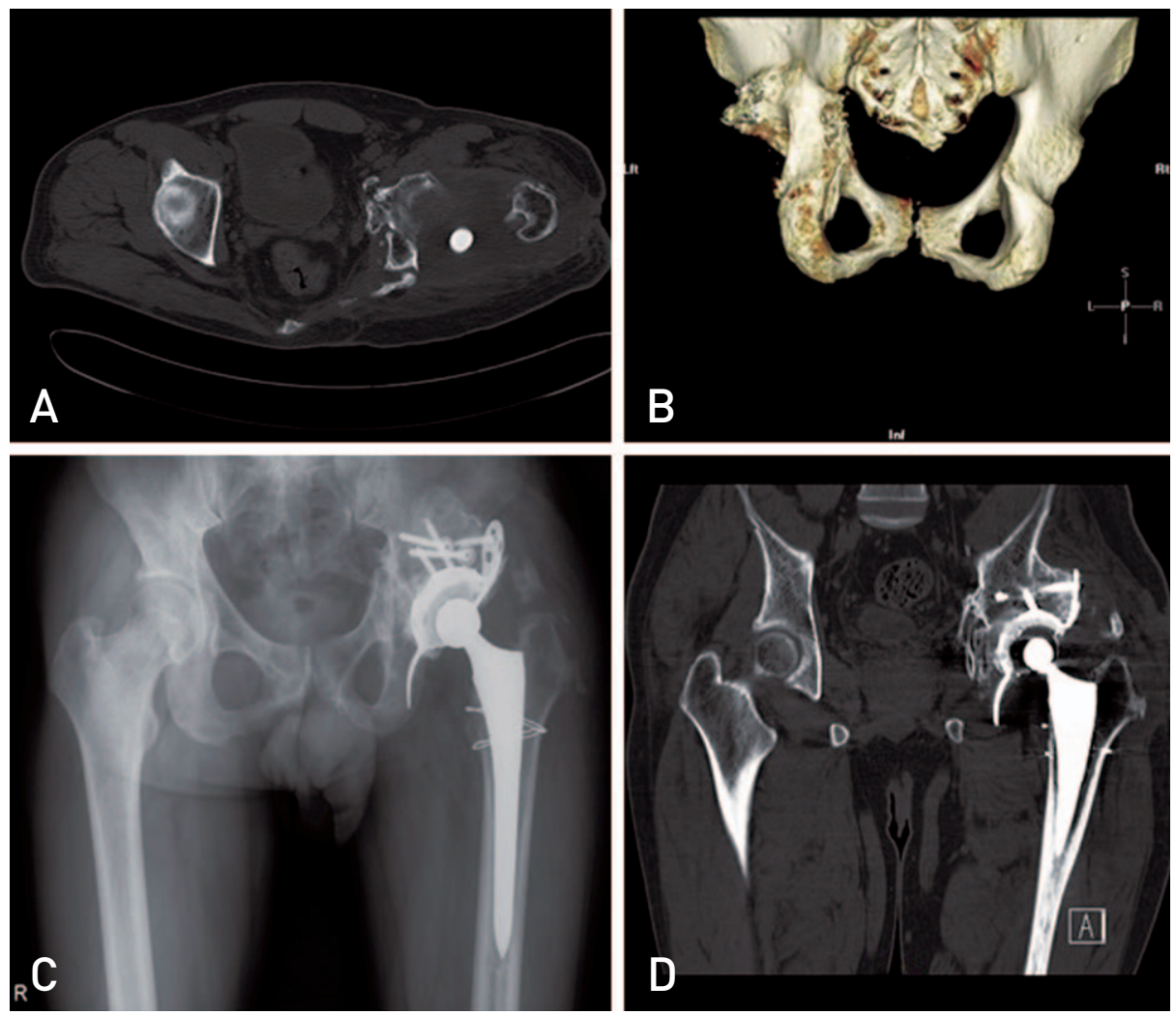

Fig. 5. (A, B) Computed tomography (CT) scan images showing severe bone defect in the postero-superior column of acetabulam. (C) Radiograph taken after revision with structural allograft and anti-protrusio cage. (D) CT scan image done after 1 year showing a good fixation of cage between host bone and structural allograft. 


\section{Hip \& Pelvis}

Hip Pelvis 28(1): 1-14, 2016

and radiographic evaluations. At the time of the latest follow up, 4 hips were failed and only one hip survived for 8 years (Fig. 4, 6). We have no experience with morselized allografts with mesh for major segmental acetabular defect.

In conclusion, a high rate of failure has been noted when structural grafts replacing more than $50 \%$ of the acetabulum with porous-coated acetabular component has been inserted without a cage. The high rate of failure is believed to be secondary to poor incorporation and delayed resorption of a structural allograft.

\section{REINFORCEMENT RINGS OR CAGES WITH ALLOGRAFT}

The armamentarium for treatment large bone defects (Paprosky type II C or III) has traditionally included acetabular roof reinforcement ring (Ganz ring, Müller ring) and anti-protrusion cages. These expansile implants are indicated for cases in which stability cannot be obtained with a cementless hemispheric cup or in situations where the remaining host bone is too compromised to achieve biologic fixation of a porous implant. Anti-protrusion cages provide a larger contact area between the remaining host bone and the implants, which potentially reduces the likelihood of implant migration (Fig. 5).

The Müller or Ganz ring and Kerboull plate were used in segmental defects, and the Burch-Schneider cage was used in major defects. The Müller or Ganz ring gives its best results in cavitary and anterior segmental defects. They were designed for reconstruction of acetabular floor or cavitary defects and smaller defects of the lateral border of the acetabular rim. Further on, it allows the anatomical restoration of the center of rotation. An intact inferior part of the acetabulum is required for anchoring the hook in the incisura acetabula. The BurchSchneider anti-protrusio cage is indicated in major bone defects, but its use requires experience and good exposure, since the screws must be placed in zones with
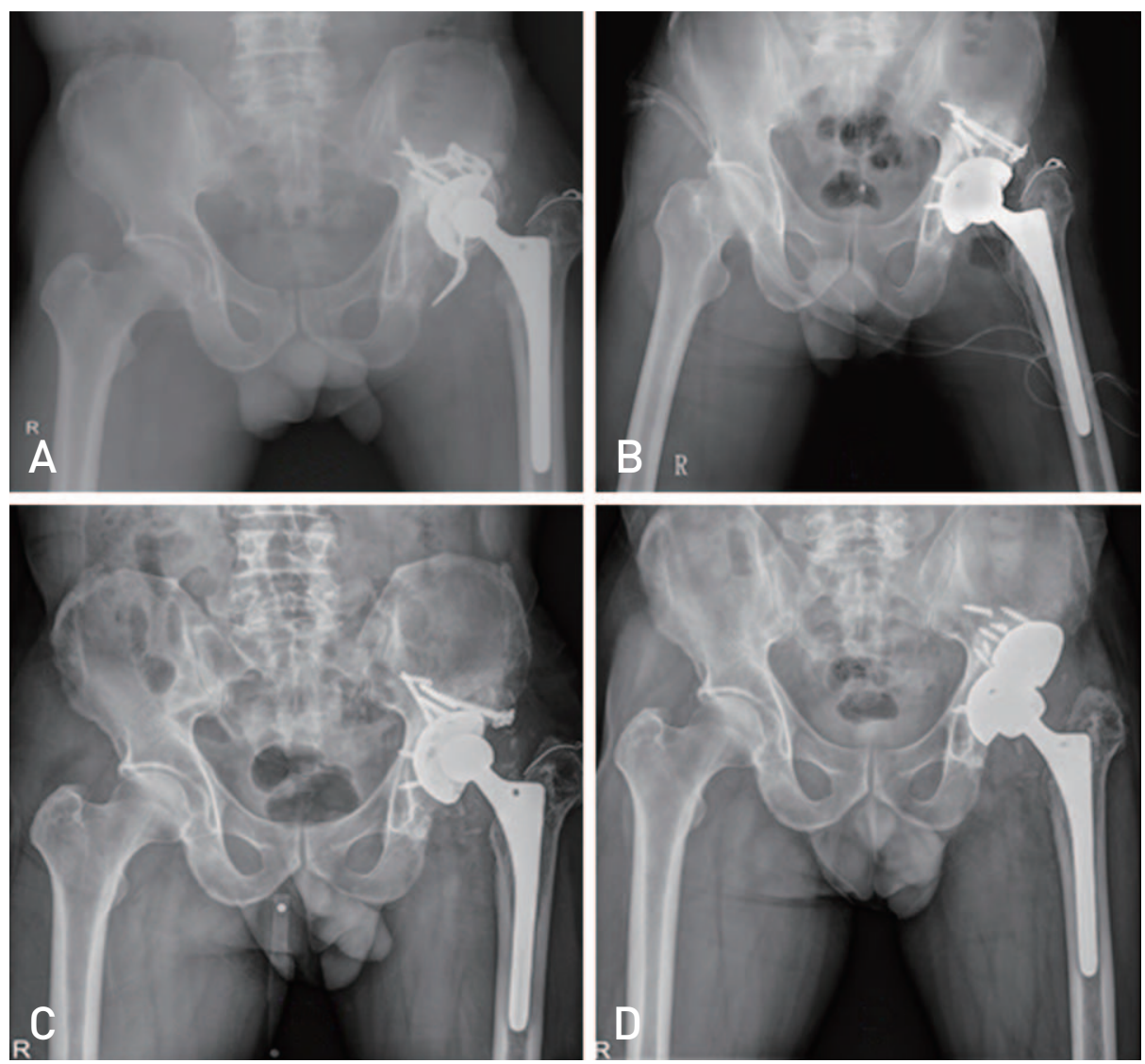

Fig. 6. (A) Radiograph showing lysis and loosening of the anti-protrusio cage. (B) Post-operative radiograph done after revision with structural allograft and a cementless acetabular cup. (C) Follow up radiograph at 4 years, showing loosening of the acetabular cup. (D) Post-operative radiograph taken after revision with tantalum metal block and cementless acetabular cup. 


\section{Hip \& Pelvis}

Won Yong Shon et al. Acetabular Reconstruction in Total Hip Arthroplasty

good bone stock.

In general, structural grafts replacing more than $50 \%$ of the acetabulum require protection by a cage. The major advantages of rings and cages are, the cage and ring allow for restoration of hip center; they provide uniform load to the allograft stimulating bone remodeling and incorporation into host bone $e^{5)}$, allows the surgeon to cement a liner in any position independent of the ring position and the elution of local antibiotics from the cement. The cage protects either the morsellized or structural allograft while it remodels, and if the cage fails cementless revision can be done ${ }^{28}$.

The major disadvantage is the risk of cage fracture or loosening resulting from lack of biologic fixation (Fig. 7). However, if the graft remodels by the time of ring fracture, a subsequent standard cementless acetabular revision is often possible.

The indications for when to use bulk allograft and when to use morsellized allograft with a reconstruction cage are unclear. The theoretical advantages of bulk allograft are restoration of large areas of acetabular bone stock and immediate structural support. The disadvantages of structural allograft are slow revascularization and prolonged presence of necrotic bone tissue with possible graft weakening over time ${ }^{15,29)}$.

Reconstruction cages have also been used with morsellized allograft for massive acetabular deficiencies (Fig. 8). Cancellous allografts incorporate more quickly and may reconstitute bone voids in the acetabulum but do not on their own provide structural stability ${ }^{15}$.

In the setting of combined segmental and cavitary defects, IBG with compressed particulate graft used in conjunction with an anti-protrusio cage construct, the healthy host bone is bridged by the cage implant, which protects the grafted area while consolidation and reconstitution of the acetabular bed occur $^{30)}$ (Fig. 9).

Impacted morsellized allografts provide an effective and widely accepted method to restore bone stock, and have yielded good clinical and radiological results ${ }^{31}$. However, several authors reported that in revisions with
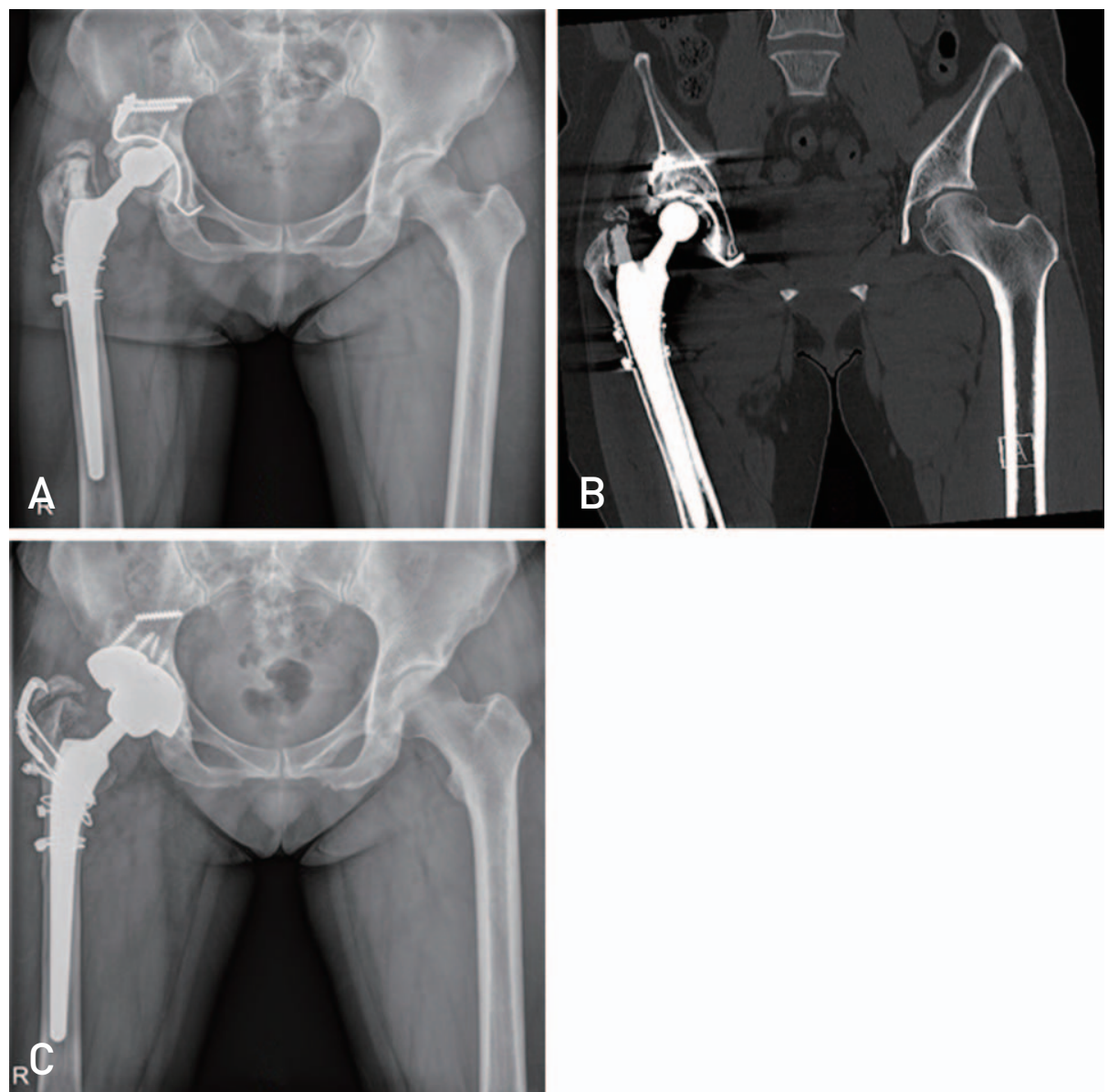

Fig. 7. (A, B) Radiograph and computed tomography respectively showing failure of Kerboull plate because of fracture of screw at 11 years after operation. (C) Post-operative radiograph after revision with metal augment. 


\section{Hip \& Pelvis}

Hip Pelvis 28(1): 1-14, 2016
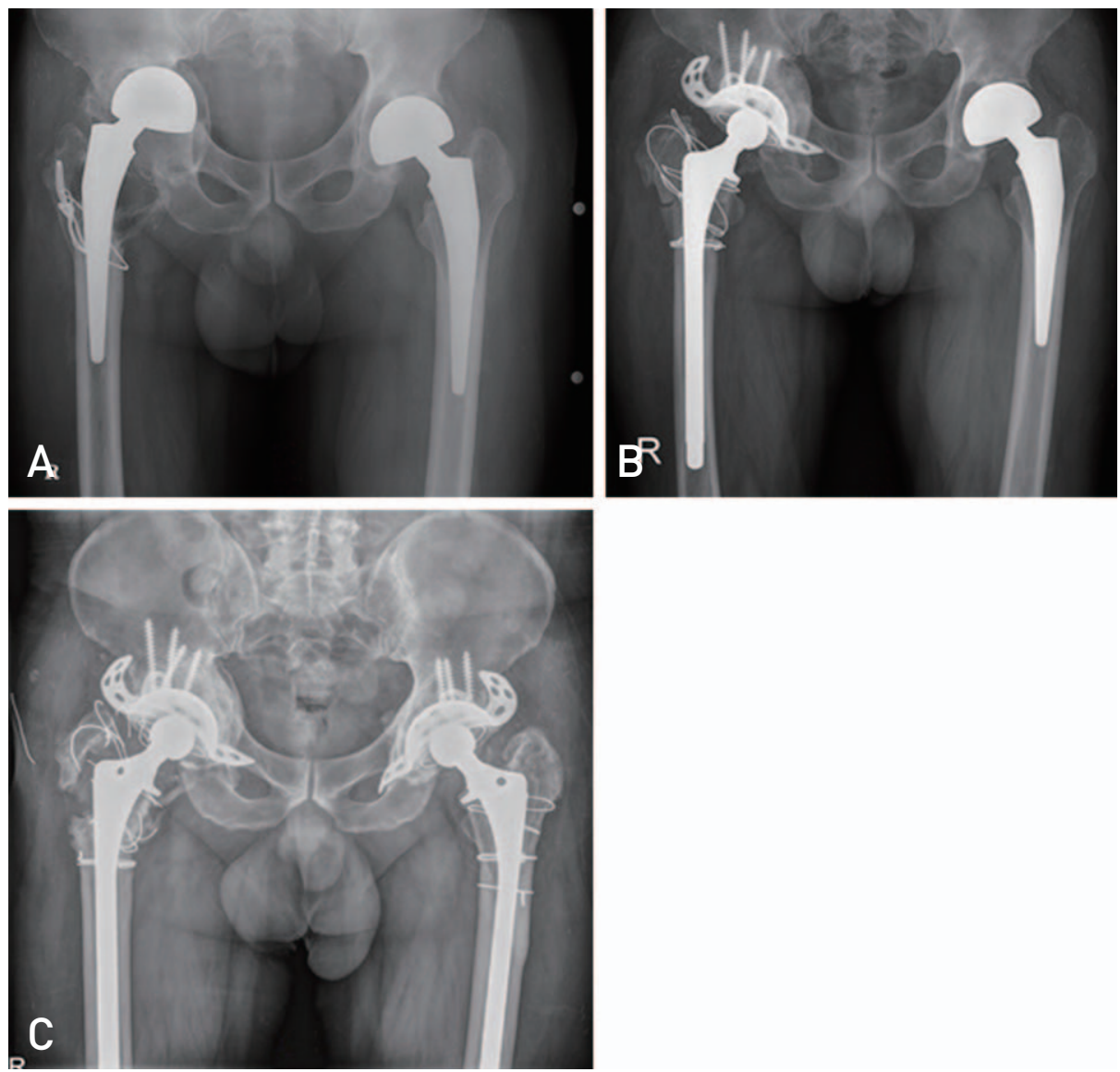

Fig. 8. (A) Radiograph showing superior and medial migration of bipolar prosthesis. (B) Radiograph taken after revision with impaction bone grafting and anti-protrusio cage. (C) Follow up radiograph at 10 years showing a well organised graft with no evidence of implant loosening.
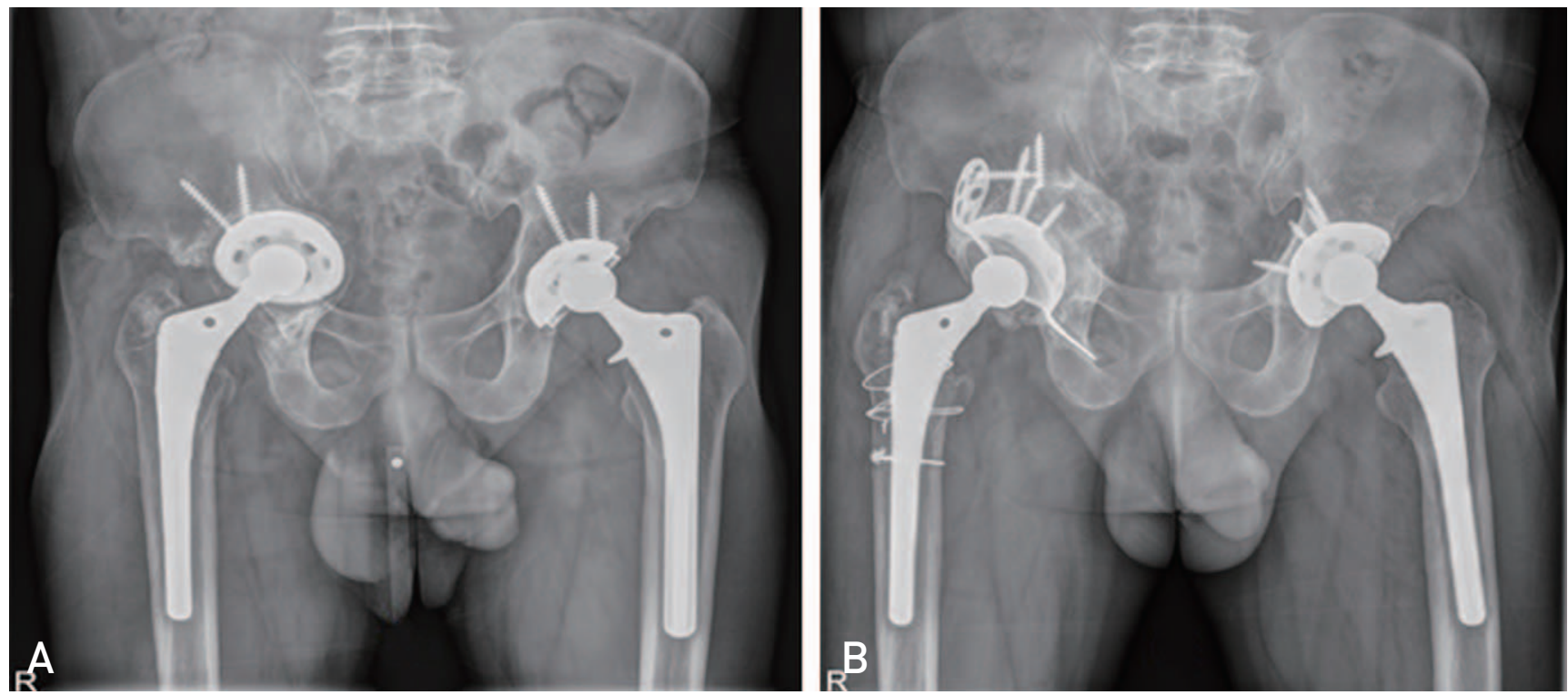

Fig. 9. (A) Radiograph showing supero-medial migration of acetabular component. (B) Follow up radiograph at 1 year postoperaion showing no resorption of allograft and a good functioning anti-protrusio cage. 
large acetabular bone defects or pelvic discontinuity, the impaction morselized bone grafting technique carries an increased risk of high failure ${ }^{3,32}$. And so, in cases with morsellized allograft with a reconstruction cage, antiprotrusio cages should have a larger contact area with the remaining host bone and rigid primary fixation with at least 3-4 screws.

The rigid placement of the dome screws in the use of the reinforcement cages is of crucial importance to prevent micro-motion of the cage and subsequent defragmentation or resorption of the graft. Mechanically, the reinforcement ring should be considered as an internal fixation plate for the acetabulum, into which the anterior and posterior columns are secured. In the absence of adequate mechanical integrity, the reconstruction is doomed to fail.

Our experience suggests that using bulk grafts from femoral head allografts itself for acetabular reconstruction is a mechanically stable reconstruction method for large acetabular bone defects (Fig. 5). However, we agree that a few reports also have noted that revasculation and osseous ingrowth in large bulk allografts can take several years and may contribute to graft collapse. It has been reported that morsellised allografts are superior in terms of revasculation compared to bulk grafts ${ }^{33,34}$.

Literature review showed that the first long-term results using Burch-Schneider cages for acetabular revision arthroplasty were published in 1992 by Berry and Müller ${ }^{35)}$, in 1995 by Peters et al. ${ }^{36)}$, and in 1998 by Gill et $\mathrm{al}^{377}$. They showed implant survival rates of $76 \%$ (32 hips) after 5 years, 100\% (28 hips) after 33 months and $79 \%$ (58 hips) after 8.5 years on average. Recently reported follow-up periods of 10 years or more demonstrated survivorship rates of $87.5 \%$ (56 hips) after 11.7 years and $72.2 \%$ (18 hips) after 13.5 years published by Regis et $\mathrm{al}^{38}$.

Rates of complications after acetabular revisions using structural grafts and cage devices are high. Currentgeneration cages or plates lack the potential for bone ingrowth and therefore ultimately loosen or break ${ }^{29)}$ (Fig. 7). The introduction of porous-coated implants may increase the longevity of these constructs ${ }^{39}$.

Between July 2000 and December 2013, 31 patients (representing 32 hips) underwent revision THA using reinforcement rings or cages for acetabular reconstruction. The patients had a mean age of 51.4 years (range, 31-74 years). Sixteen hips had a Paprosky type II B and C defect, nine hips had type III A defect, 7 hips had type III B defect. After a mean follow up of 77 months (range, 15-180 months), all patients except for 4 cases of fixation failure, 2 cases of infection, significantly improved, based on the mean Harris hip score (41 points vs. 86 points), 26 hips ( $81 \%$ ) showed radiographically stable fixation at average 105 months follow up.

Six hips with a failed cage underwent re-revision surgery using a standard cementless acetabular component and porous metal block.

In conclusion, a structural allograft with BurchSchneider anti-protrusio cage for complex acetabular defect is a technically demanding procedure with a 6-year survival rate of $81 \%$. In cases of failed cage reconstruction with freeze-drying allografts, most allografts were poorly incorporated and resorbed.

\section{CEMENTLESS RECONSTRUCTION WITH MODULAR POROUS METAL AUGMENTS}

More recently porous metals have been utilised, combined with porous augments to allow improved implant stability, either by the filling of contained defects, or the use of the augment as a structural graft material in segmental defects.

Porous tantalum has emerged as a powerful tool for reconstruction of the failed acetabular component. The increased porosity, high coefficient of friction, and favorable elastic modulus of porous tantalum compared with traditional titanium mesh or cobalt chromium acetabular components allow for greater bone in-growth potential, implant stability, and host bone preservation when using porous tantalum shells ${ }^{40}$.

Cementless hips using TM cups with or without augments provide good stability with biologic fixation. Satisfactory results have been reported with a 10 year follow up for defects treated with TM augments and cemented THA ${ }^{41}$.

To supplement acetabular fixation when there is segmental bone loss, acetabular augments can be used to fill specific defects. In the past, structural allografts served this purpose. These augments have essentially replaced the need for structural allograft and can be used alone or in combination with other augments, and reamers are available to prepare the acetabular defect where augments will be placed (Fig. 6, 10). The augments are then impacted into the defect and secured with screws. Once the augments are fixed with screws, second-generation porous coated 


\section{Hip \& Pelvis}

Hip Pelvis 28(1): 1-14, 2016

hemispherical cup can be press fitted into the acetabulum and cement placed at the augment-cup interface. Studies evaluating the use of acetabular augments have shown radiographically stable fixation at 2-year follow-up when used alone ${ }^{7)}$, when combined with impaction grafting $^{42}$, and when used with a cage-cup construct ${ }^{43}$.

Between 2011 and 2014, 18 patients (representing 18 hips) underwent primary or revision THA using Tantalum metal block augmentations. The patients had a mean age of 59 years (range, 37-79 years). All hips had a Paprosky type III A defect, or type III B defect, after minimum 7 months follow up, all patients significantly improved, with no radiographic loosening.

In conclusion, the very high surface friction guaranteed by the material and the supplemental stability provided by transacetabular screws seem to be sufficient to allow satisfactory re-implantation even in severely damaged pelvis.

\section{CUP-CAGE RECONSTRUCTION}

The preferred option to provide acetabular fixation is to use a cup-cage construct. In this method, a secondgeneration porous cup is fixed in the pelvis. If there is minimal stability of the implant, an acetabular cage can be placed on top of the cup and secured with screw fixation into the ilium and ischium.

The cup-cage construct can be used to manage not only Paprosky type III A and III B bone loss but also pelvic discontinuity. Bellester Alfaro and Sueiro Fernádez ${ }^{42)}$ described the use of the "cup-cage" construct combined with TM buttress augments in five chronic pelvic discontinuities and at a mean 26 months follow-up there were no failures.

We have no experience because of non-availability of proper cage for appropriate size acetabular hemisphere cups in our country.

\section{SADDLE PROSTHESIS}

The saddle prosthesis was developed in the late $70 \mathrm{~s}$ for the reconstruction of large peri-acetabular tumour resections. The saddle shaped implant is typically
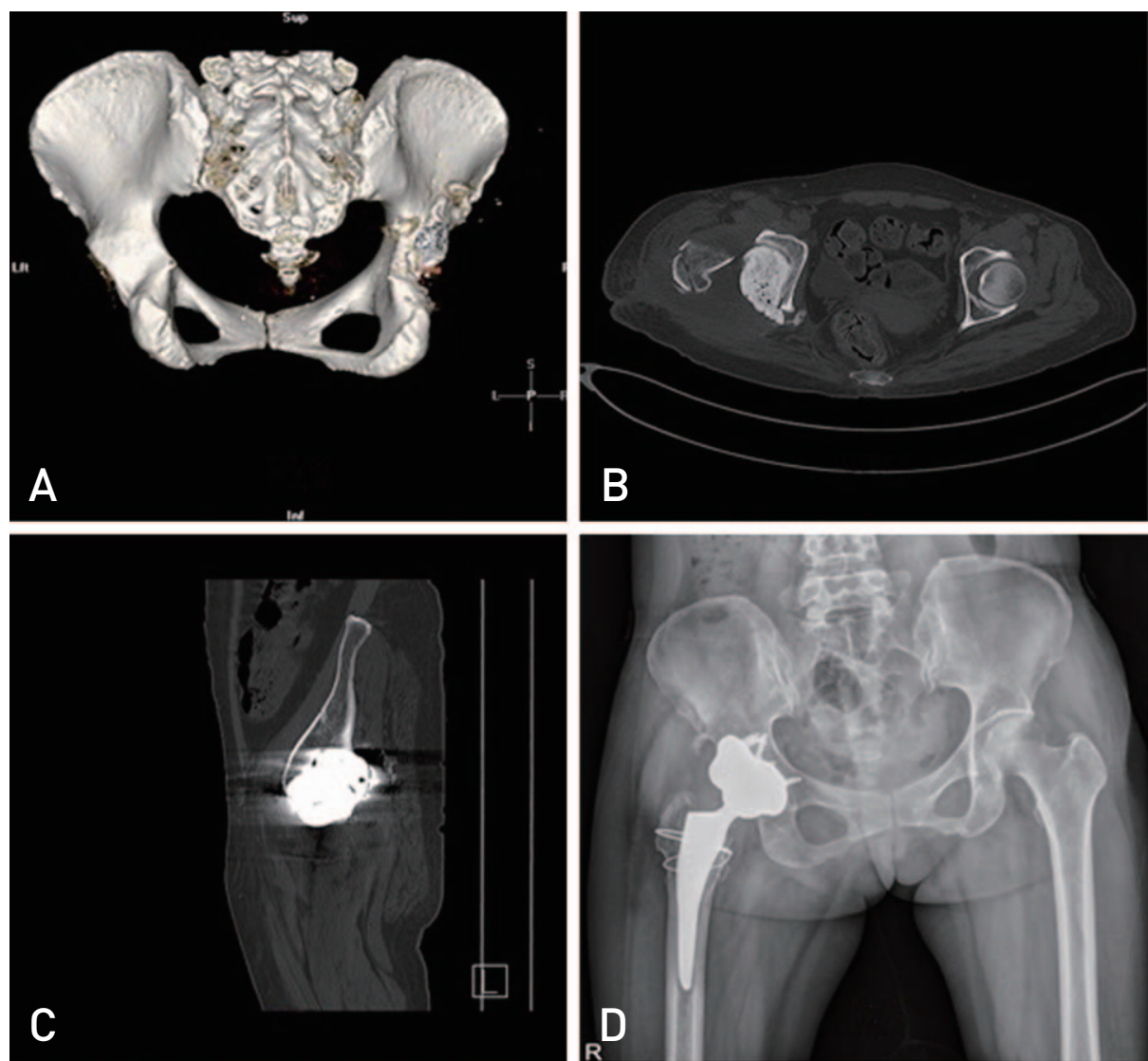

Fig. 10. (A, B, C) Computed tomography scan images showing postero-superior column defect in the acetabulam. (D) Postoperative radiograph done after revision with tantalum metal block and a cementless acetabular cup. 


\section{Hip \& Pelvis}

Won Yong Shon et al. Acetabular Reconstruction in Total Hip Arthroplasty
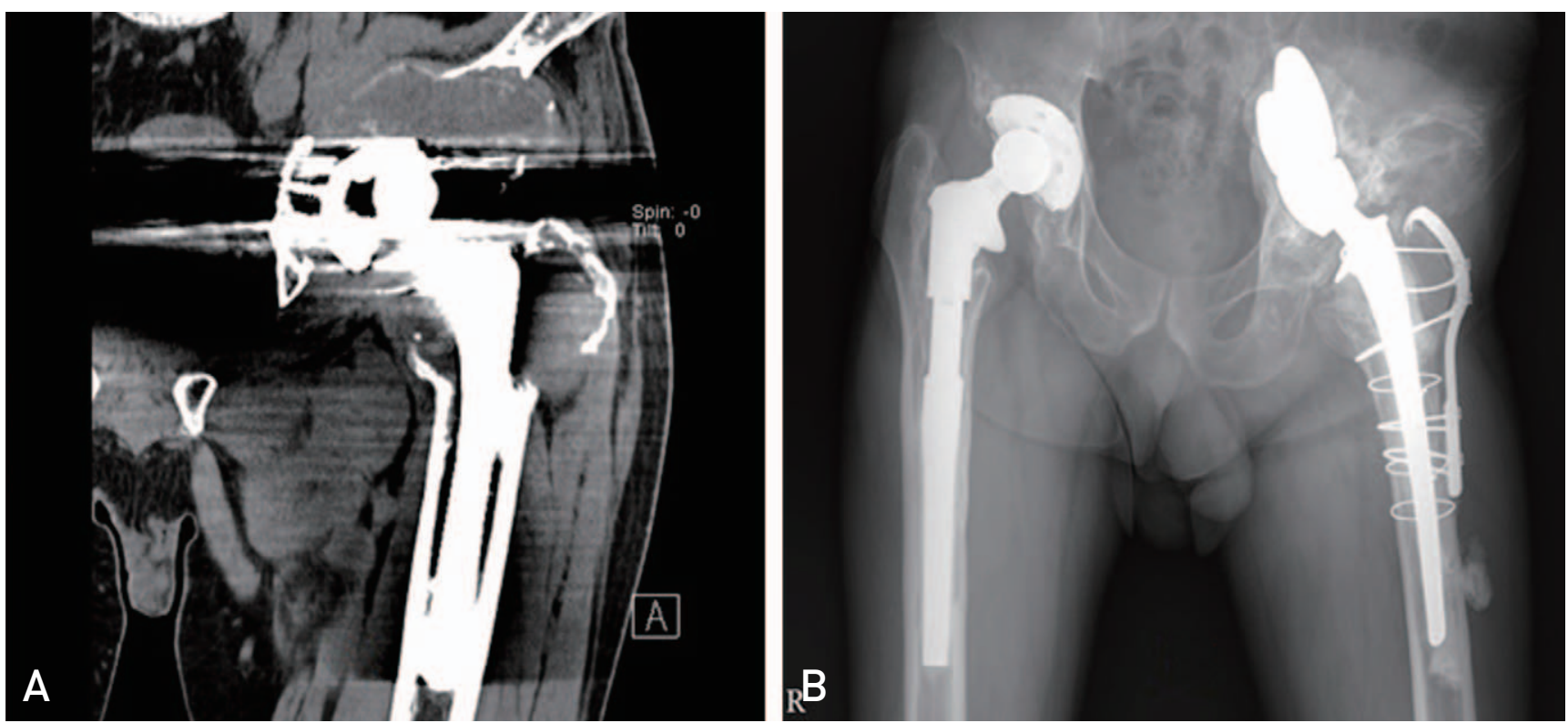

Fig. 11. (A) Computed tomography scan image showing pelvic discontinuity due to severe osteolysis. (B) Follow up radiograph at 6 years after revision with saddle prosthesis.

supported by the remnant of the iliac bone at or above the level of the sciatic notch. The modular saddle prosthesis has a connection with the regular femoral component. However, reconstruction with saddle prostheses after major pelvic defect has a high risk of complications and poor long-term functional outcome with limited hip flexion. Superior migration of the reconstruction in osteoporotic or metastatic bone is frequently reported ${ }^{44)}$ (Fig. 11).

Between 2000 and 2005, we treated 2 patients with saddle prosthesis for acetabular deficiency in case of pelvic discontinuity. One patient complained of severe hip pain and was revised at another hospital. The second patient showed poor long-term function with marked limitation of hip flexion. We no longer use the saddle prosthesis for acetabular reconstruction in revision surgery.

\section{CONFLICT OF INTEREST}

The authors declare that there is no potential conflict of interest relevant to this article.

\section{REFERENCES}

1. Slooff TJ, Schimmel JW, Buma P. Cemented fixation with bone grafts. Orthop Clin North Am. 1993;24:667-77.

2. van Egmond N, De Kam DC, Gardeniers JW, Schreurs BW. Revisions of extensive acetabular defects with impaction grafting and a cement cup. Clin Orthop Relat Res. 2011; 469:562-73.

3. van Haaren EH, Heyligers IC, Alexander FG, Wuisman PI. High rate of failure of impaction grafting in large acetabular defects. J Bone Joint Surg Br. 2007;89:296-300.

4. Bostrom MP, Lehman AP, Buly RL, Lyman S, Nestor BJ. Acetabular revision with the Contour antiprotrusio cage: 2- to 5-year followup. Clin Orthop Relat Res. 2006;453: 188-94.

5. Issack PS, Nousiainen M, Beksac B, Helfet DL, Sculco TP, Buly RL. Acetabular component revision in total hip arthroplasty. Part II: management of major bone loss and pelvic discontinuity. Am J Orthop (Belle Mead NJ). 2009;38:550-6.

6. Sporer SM. How to do a revision total hip arthroplasty: revision of the acetabulum. J Bone Joint Surg Am. 2011; 93:1359-66.

7. Borland WS, Bhattacharya R, Holland JP, Brewster NT. Use of porous trabecular metal augments with impaction bone grafting in management of acetabular bone loss. Acta Orthop. 2012;83:347-52.

8. Abolghasemian M, Tangsataporn S, Sternheim A, Backstein D, Safir O, Gross AE. Combined trabecular metal acetabular shell and augment for acetabular revision with substantial bone loss: a mid-term review. Bone Joint J. 2013;95-B:166-72.

9. Yun HH, Shon WY, Hong SJ, Yoon JR, Yang JH. Relationship between the pelvic osteolytic volume on computed tomography and clinical outcome in patients with cementless acetabular components. Int Orthop. 2011; 35:1453-9.

10. Suh DH, Han SB, Yun HH, Chun SK, Shon WY. Characterization of progression of pelvic osteolysis after cementless total hip arthroplasty: computed tomographic study. J Arthroplasty. 2013;28:1851-5. 
11. Reiley MA, Bond D, Branick RI, Wilson EH. Vascular complications following total hip arthroplasty. A review of the literature and a report of two cases. Clin Orthop Relat Res. 1984;(186):23-8.

12. Patel S, Sukeik M, Haddad FS. Initial implant stability predicts migration but not failure in cementless acetabular revision with bone grafting. J Arthroplasty. 2013;28:832-7.

13. Mazhar Tokgözoğlu A, Aydin M, Atilla B, Caner B. Scintigraphic evaluation of impaction grafting for total hip arthroplasty revision. Arch Orthop Trauma Surg. 2000; 120:416-9.

14. Goldberg VM. Selection of bone grafts for revision total hip arthroplasty. Clin Orthop Relat Res. 2000;(381):68-76.

15. Stevenson S. Biology of bone grafts. Orthop Clin North Am. 1999;30:543-52.

16. Schimmel JW, Buma P, Versleyen D, Huiskes R, Slooff TJ. Acetabular reconstruction with impacted morselized cancellous allografts in cemented hip arthroplasty: a histological and biomechanical study on the goat. J Arthroplasty. 1998;13:438-48.

17. Etienne G, Ragland PS, Mont MA. Use of cancellous bone chips and demineralized bone matrix in the treatment of acetabular osteolysis: preliminary 2-year follow-up. Orthopedics. 2004;27(1 Suppl):s123-6.

18. Jasty M, Harris WH. Total hip reconstruction using frozen femoral head allografts in patients with acetabular bone loss. Orthop Clin North Am. 1987;18:291-9.

19. Avci S, Connors N, Petty W. 2- to 10-year follow-up study of acetabular revisions using allograft bone to repair bone defects. J Arthroplasty. 1998;13:61-9.

20. Buttaro MA, Comba F, Pusso R, Piccaluga F. Acetabular revision with metal mesh, impaction bone grafting, and a cemented cup. Clin Orthop Relat Res. 2008;466:2482-90.

21. Brubaker SM, Brown TE, Manaswi A, Mihalko WM, Cui $\mathrm{Q}$, Saleh KJ. Treatment options and allograft use in revision total hip arthroplasty the acetabulum. J Arthroplasty. 2007; 22(7 Suppl 3):52-6.

22. Murphy SB. Management of acetabular bone stock deficiency. J Arthroplasty. 2005;20(4 Suppl 2):85-90.

23. Paprosky WG, Magnus RE. Principles of bone grafting in revision total hip arthroplasty. Acetabular technique. Clin Orthop Relat Res. 1994;(298):147-55.

24. Sporer SM, O'Rourke M, Chong P, Paprosky WG. The use of structural distal femoral allografts for acetabular reconstruction. Average ten-year follow-up. J Bone Joint Surg Am. 2005;87:760-5.

25. O'Rourke MR, Paprosky WG, Rosenberg AG. Use of structural allografts in acetabular revision surgery. Clin Orthop Relat Res. 2004;(420):113-21.

26. Pollock FH, Whiteside LA. The fate of massive allografts in total hip acetabular revision surgery. J Arthroplasty. 1992;7:271-6.

27. Garbuz D, Morsi E, Gross AE. Revision of the acetabular component of a total hip arthroplasty with a massive structural allograft. Study with a minimum five-year follow-up. J Bone Joint Surg Am. 1996;78:693-7.

28. Gross AE. Restoration of acetabular bone loss 2005. J Arthroplasty. 2006;21(4 Suppl 1):117-20.
29. Gross AE, Goodman S. The current role of structural grafts and cages in revision arthroplasty of the hip. Clin Orthop Relat Res. 2004;(429):193-200.

30. Oakes DA, Cabanela ME. Impaction bone grafting for revision hip arthroplasty: biology and clinical applications. J Am Acad Orthop Surg. 2006; 14:620-8.

31. Patil N, Hwang K, Goodman SB. Cancellous impaction bone grafting of acetabular defects in complex primary and revision total hip arthroplasty. Orthopedics. 2012;35:e306-12.

32.Zehntner MK, Ganz R. Midterm results (5.5-10 years) of acetabular allograft reconstruction with the acetabular reinforcement ring during total hip revision. J Arthroplasty. 1994;9:469-79.

33. Tägil M. The morselized and impacted bone graft. Animal experiments on proteins, impaction and load. Acta Orthop Scand Suppl. 2000;290:1-40.

34. Jasty M, Harris WH. Salvage total hip reconstruction in patients with major acetabular bone deficiency using structural femoral head allografts. J Bone Joint Surg Br. 1990;72:63-7.

35. Berry DJ, Müller ME. Revision arthroplasty using an antiprotrusio cage for massive acetabular bone deficiency. $J$ Bone Joint Surg Br. 1992;74:711-5.

36. Peters CL, Curtain M, Samuelson KM. Acetabular revision with the Burch-Schnieder antiprotrusio cage and cancellous allograft bone. J Arthroplasty. 1995;10:307-12.

37. Gill TJ, Sledge JB, Müller ME. The Bürch-Schneider antiprotrusio cage in revision total hip arthroplasty: indications, principles and long-term results. J Bone Joint Surg Br. 1998;80:946-53.

38. Regis D, Sandri A, Bonetti I, Bortolami O, Bartolozzi P. A minimum of 10-year follow-up of the Burch-Schneider cage and bulk allografts for the revision of pelvic discontinuity. J Arthroplasty. 2012;27:1057-63.e1.

39. Nehme A, Lewallen DG, Hanssen AD. Modular porous metal augments for treatment of severe acetabular bone loss during revision hip arthroplasty. Clin Orthop Relat Res. 2004;(429):201-8.

40. Bobyn JD, Stackpool GJ, Hacking SA, Tanzer M, Krygier JJ. Characteristics of bone ingrowth and interface mechanics of a new porous tantalum biomaterial. J Bone Joint Surg Br. 1999;81:907-14.

41. Van Kleunen JP, Lee GC, Lementowski PW, Nelson CL, Garino JP. Acetabular revisions using trabecular metal cups and augments. J Arthroplasty. 2009;24(6 Suppl):64-8.

42. Ballester Alfaro JJ, Sueiro Fernández J. Trabecular Metal buttress augment and the Trabecular Metal cup-cage construct in revision hip arthroplasty for severe acetabular bone loss and pelvic discontinuity. Hip Int. 2010;20 Suppl 7:S119-27.

43. Malhotra R, Kancherla R, Kumar V, Soral A. Trabecular metal acetabular revision system (cup-cage construct) to address the massive acetabular defects in revision arthroplasty. Indian J Orthop. 2012;46:483-6.

44. Jansen JA, van de Sande MA, Dijkstra PD. Poor long-term clinical results of saddle prosthesis after resection of periacetabular tumors. Clin Orthop Relat Res. 2013;471: 324-31. 